\title{
Potential Mechanisms Involved in Ceramide-induced Apoptosis in Human Colon Cancer HT29 Cells ${ }^{1}$
}

\author{
JING WANG $^{*, 2}$, XIAO-WEN LV ${ }^{\ddagger, 2}$, AND YU-GUO DU* \\ * State Key Laboratory of Environmental Chemistry and Ecotoxicology, Research Center for Eco-Environmental \\ Sciences, Chinese Academy of Sciences, Beijing 100085, China; ${ }^{*}$ Feed Research Institute, \\ Chinese Academy of Agricultural Sciences, Beijing 100081, China
}

\begin{abstract}
Objective To investigate the potential mechanisms of cell death after the treatment with ceramide. Methods MTT assay, DNA ladder, reporter assay, FACS and Western blot assay were employed to investigate the potential mechanisms of cell death after the treatment with C2-ceramide. Results A short-time treatment with C2-ceramide induced cell death, which was associated with p38 MAP kinase activation, but had no links with typical caspase activation or PARP degradation. Rather than caspase inhibitor, Inhibitor of p38 MAP kinase blocked cell death induced by a short-time treatment with ceramide $(<12 \mathrm{~h})$. However, inhibition of p38 MAP kinase could not block cell death induced by a prolonged treatment with ceramide $(>12 \mathrm{~h})$. Moreover, incubation of cells with ceramide for a long time $(>12 \mathrm{~h})$ increased subG1, but reduced $\mathrm{S}$ phase accompanied by caspase-dependent and caspase-independent changes including NF $\mathrm{B}$ activation. Conclusion Ceramide-induced cell apoptosis involves both caspase-dependent and -independent signaling pathway. Caspase-independent cell death occurring in a relatively early stage, which is mediated via p38 MAP kinase, can progress into a stage involving both caspase-dependent and -independent mechanisms accompanied by cell signaling of MAPKs and NFKB.
\end{abstract}

Key words: Ceramide; HT29 cells; Apoptosis; Cell signaling; p38 MAPK; NFкB

\section{INTRODUCTION}

Ceramide, a metabolite of sphingolipids generated by degradation of sphingomyelin through the action of sphingomyelinases, condensation of sphinganine or sphingosine and fatty acyl-CoA via ceramide synthesis, has emerged as a novel lipid second messenger with a specific role in cell signaling implicated in cell growth, proliferation, apoptosis and other cell responses ${ }^{[1]}$. The biological effects of ceramide depends on many parameters, such as cell type, nature of cell receptors and their concentration, suggesting the existence of multiple downstream targets activated through distinct intracellular pathways. C2-ceramide, a non-natural but cell-permeable analog of the endogenous long-chain ceramides, has been used in a variety of studies to display the biological effects of the endogenous ceramide.

One of the most clearly illustrated targets of ceramide is cell death ${ }^{[2-5]}$. Many factors for apoptosis, including TNF- $\alpha$, CD95/Fas/APO-1, serum deprivation, chemotherapeutic drugs, radiations, heat shock, and oxidative stress, appear to induce a rapid rise of intracellular ceramide concentration by regulating one or more enzymes of ceramide metabolism ${ }^{[6-7]}$. Interestingly, ceramide not only plays an important role in one or several stages of apoptosis, but also in caspase-independent and/or non-apoptotic cell death. Although the main biological function of ceramide appears to be linked to its potency to induce cell death, its actual relevance as a regulator of cell death is controversial.

The implications of JNK and p38 MAPK in ceramide-induced cell death in various cell types have been revealed by pharmacological and molecular assays $^{[8-10]}$. However, it has also been demonstrated that p38 MAPK may not be essential for ceramide-induced cell death in U937 and MC/9 cells ${ }^{[11-12]}$. On the other hand, it has been reported that NFKB activation is involved in apoptosis inhibition ${ }^{[13-14]}$. However, consisting activation of $\mathrm{NF \kappa B}$ could also induce

${ }^{1}$ This study was partially supported by the Knowledge Innovation Program of the Chinese Academy of Sciences (RCEES-QN-200712) and the Special Funds for Young Scholars of RCEES, CAS.

Correspondence should be addressed to Jing WANG, No. 18 Shuangqing Road, Beijing 100085, China. Tel: 86-10-62849321. Fax: 86-10-62923563. E-mail: avaecn@gmail.com

${ }^{2}$ Both of authors contributed equally to this work.

Biographical note of the first authors: Jing WANG, born in 1976, Ph. D, majoring in cellular signal transduction and apoptosis. Xiao-Wen LV, born in 1976, Ph. D, majoring in feeding safety and assessment. 
pre-apoptotic gene expression in some neuron cells ${ }^{[15-16]}$. Indeed, the mechanism of ceramide-induced apoptosis is still controversial and various hypotheses have been postulated ${ }^{[17-19]}$.

We have previously found some data about MAPK signaling in apoptotic HT29 cells induced by C2-ceramide ${ }^{[20]}$. However, neither MAPK nor NFKB signaling has been investigated in details. The present study is designed to examine the potential mechanisms of HT29 cell death induced by C2-ceramide treatment. Our data demonstrate that ceramide-induced apoptotic cell death involves both caspase-dependent and -independent signaling pathway. Caspase-independent cell death occurring in an early stage activated by $\mathrm{p} 38$ MAPK can progress into a stage involving both caspase-dependent and -independent mechanism accompanied with cell signaling of_MAPKs and NFKB.

\section{MATERIALS AND METHODS}

\section{Reagents}

C2-ceramide was purchased from Sigma Co. PD98059, SB203580 and zVAD-fmk were from Alexis Biochemical. Anti-NFKB antibody was from Cell Signaling. Anti-CDK7, procaspase-3 (32kDa), cleaved caspase-3 $(17 \mathrm{kDa})$ and $\beta$-actin antibodies were from Santa Cruz, Inc. Anti-phosphorylatedERK, JNK, p38 antibodies were from New England Biolabs, Inc. Anti-cleaved PARP antibody was from Abcam. MTT, propiudium iodide (PI), IкB inhibitor PDTC and other chemicals were all from Sigma.

\section{Cell Culture and Treatment}

HT29 cells (originally from ATCC) obtained from the Chinese Academy of Medical Sciences were maintained in Dulbecco's minimal essential medium supplemented with $10 \%$ FBS. Subculture of cells was performed by enzymatic digestion (trypsin / EDTA solution: $0.25 \% / 0.02 \%$ ). C2-ceramide and other reagents dissolved in ethanol or dimethyl sulfoxide (DMSO) were used without filtration. Final concentration of DMSO or ethanol in culture medium was $<0.3 \%$.

\section{Determination of Cell Death}

Cell viability was ascertained by MTT assay (20 $\mu \mathrm{L}$ of $5 \mathrm{mg} / \mathrm{mL}$ MTT in PBS) and the absorbance was measured at $570 \mathrm{~nm}$.

\section{Flow Cytometric Analysis for Apoptosis}

(1) PI staining: Cells were collected after treatment and washed 3 times with PBS, incubated with PBS containing $100 \mu \mathrm{g} / \mathrm{mL}$ propidium iodide (PI), 1\%Triton X-100, $100 \mathrm{U} / \mathrm{mL}$ RNase for $30 \mathrm{~min}$ at $37{ }^{\circ} \mathrm{C}$, followed by FACS analysis.
(2) Annexin V FITC labeling: Phosphatidylserine (PS) expression on the external surface of cells was detected in terms of binding to FITC-labeled annexin V. Cells were collected and washed once with cold PBS, and centrifuged to collect the cell pellet which was resuspended in a cold binding buffer $(10 \mathrm{mmol} / \mathrm{L}$ HEPES/NaOH, pH 7.4, 140 mmol/L NaCl, 5 mmol/L $\mathrm{CaCl}_{2}$ ). Annexin V-FITC (final concentration 1 $\mu \mathrm{g} / \mathrm{mL}$ ) was added and mixed gently. The tubes were then incubated for 15-20 min in the dark prior to flow cytometry.

\section{DNA Ladder Assays}

Cells were cultured with or without $\mathrm{C} 2$-ceramide $(30 \mu \mathrm{mol} / \mathrm{L})$ in the presence or absence of zVAD-fmk and p38 MAPK inhibitor SB203580 for $24 \mathrm{~h}$. Genomic DNA was extracted and resolved on $1.5 \%$ agarose gel. Cells were collected and suspended in a lysis buffer containing $10 \mathrm{mmol} / \mathrm{L}$ Tris $\cdot \mathrm{Cl}(\mathrm{pH} 8.0)$, $10 \mathrm{mmol} / \mathrm{L} \mathrm{NaCl}, 10 \mathrm{mmol} / \mathrm{L}$ EDTA, $100 \mu \mathrm{g} / \mathrm{mL}$ proteinase $\mathrm{K}, 1 \% \mathrm{SDS}$, and incubated at $37{ }^{\circ} \mathrm{C}$ for $4 \mathrm{~h}$. Lysate was extracted 3 times with phenol: choloroform $(1: 1, \mathrm{~V}: \mathrm{V})$. DNA was precipitated with $1 / 10$ volume of $3 \mathrm{~mol} / \mathrm{L}$ sodium acetate $(\mathrm{pH} 4.0)$ and 2 volumes of ethanol. The cell pellet was dissolved in $20 \mu \mathrm{L}$ TE with $2 \mathrm{mg} / \mathrm{mL}$ RNaseA and subjected to electrophoresis on $1.5 \%$ agarose gel.

\section{Western Blot}

Cell lysate in a Laemmli reducing sample buffer was separated on 12\% (for p-JNK, p-ERK, p-p38, p38, p65 NF $\kappa$ B and actin) or $6 \%$ (for cleaved PARP) SDS-PAGE. Total proteins were transferred onto PVDF membrane after electrophoresis. Western blot assay was performed using specific antibody.

\section{Immunocytochemistry by Confocal Microscopy}

Cells were seeded on coverlips into six-well culture dishes and incubated in DMEM with or without $\mathrm{C} 2$-ceramide. The coverlips were washed in PBS, fixed in methanol: acetone $(1: 1, \mathrm{v} / \mathrm{v})$ for $30 \mathrm{~min}$ and stained with primary antibody recognizing $\mathrm{p} 65 \mathrm{NF} \kappa \mathrm{B}$ for $1 \mathrm{~h}$. After washing, the glasses were incubated for $30 \mathrm{~min}$ with secondary antibody labeled with FITC. Cells were examined under a laser scanning confocal microscope (Zeiss, LSM 510).

\section{Transient Transfection and Luciferase Assay}

HT29 cells were seeded at a concentration of $1 \times 10^{5}$ cells $/ 35 \mathrm{~mm}$ dish. After $12 \mathrm{~h}$, complete medium was replaced with DMEM without FBS or antibiotic. Transfection was done using Lipofectamine reagent (Gibco BRL) mixed with pNFkB-luc and the control vector SV40 for $8 \mathrm{~h}$. After the transfection mixture was replaced with a medium containing $2 \%$ FBS, cells 
were incubated for $2 \mathrm{~h}$ with or without the inhibitor of the release of I $\mathrm{KB}$ (inhibitor $\kappa \mathrm{B}$ ) from the cytoplasmic I $\mathrm{B}-\mathrm{NF} \kappa \mathrm{B}$ complex, PDTC $(5 \mu \mathrm{mol} / \mathrm{L})$ and then with or without tested chemicals for further $24 \mathrm{~h}$. Luciferase activity was measured according to the manufacturer's protocol (Promega).

\section{RESULTS}

\section{Ceramide Induced Apoptosis in HT29 Cells}

Treatment with different concentrations of $\mathrm{C} 2$, C6, C8-ceramides for $24 \mathrm{~h}$ exhibited significant cytotoxicity against HT29 cells as suggested by MTT assay (Fig. 1A). Microscopy also showed proliferation inhibition when HT29 cells were treated with C2-ceramide for different periods of time (Fig.1B). The cytotoxicity was derived from its ability to induce apoptosis, which was demonstrated by HE staining (Fig. 1C), formation of apoptotic bodies (Fig.1D) and percentage of SubG1 phase (Fig. $1 \mathrm{E})$, respectively. Further investigation showed that C2-ceramide treatment could effectively inhibit the expression of CDK7 protein (Fig. 1F).

\section{Ceramide Induced Apoptosis via Caspase-dependent and-independent Pathway}

Cell cycle distribution of HT29 cells treated with C2-ceramide for different periods of time was shown by the accumulation of percentage of SubG1 phase and decrease in $\mathrm{S}$ phase (Table 1). However, the accumulated percentage of SubG1 phase in the earlier stage of treatment was much less than that in the late stage, which was verified by the percentage of apoptosis determined by annexin V staining (Fig. 2A). Determination of the cleaved PARP following $\mathrm{C} 2$-ceramide treatment for different periods of time as shown in Fig. 2B indicated that $\mathrm{C}$ 2-ceramide mediated enhanced PARP cleavage in the relatively late stage (more than $12 \mathrm{~h}$ ) rather than in the earlier stage (less than $12 \mathrm{~h}$ ), which was presumably attributed to enhanced caspase activity. To test directly whether caspase activation is involved in the late stage, HT29 cells were pretreated with pan-caspase inhibitor, zVAD-fmk and then with C2-ceramide, demonstrating that zVAD-fmk effectively protected HT29 cells from apoptosis suggested by annexinV-PI staining (Fig. 2C) and DNA laddering (Fig. 2D) in the relatively late stage. The finding of Western blot assay to detect real active caspase-3 also indicated that the caspase pathway was involved (Fig. 2E). However, other than the caspase-dependent pathway, the caspase-independent pathway was also involved in the relatively earlier stage (Fig. 2C, D and E).
TABLE 1

Effect of $30 \mu \mathrm{mol} / \mathrm{L}$ Ceramide on the Cell cycle Distribution in HT29 Cells

\begin{tabular}{ccc}
\hline Treatment & Sub $_{1}(\%)$ & S phase $(\%)$ \\
\hline Control $(0 \mathrm{~h})$ & 1.32 & 16.34 \\
2h & 4.35 & 12.06 \\
$4 \mathrm{~h}$ & 7.08 & 11.45 \\
$6 \mathrm{~h}$ & 5.98 & 11.87 \\
$8 \mathrm{~h}$ & 11.64 & 8.27 \\
$12 \mathrm{~h}$ & 19.86 & 8.62 \\
$20 \mathrm{~h}$ & 35.21 & 9.14 \\
$24 \mathrm{~h}$ & 54.06 & 4.93 \\
\hline
\end{tabular}

\section{MAPK Signaling in Ceramide-induced Apoptosis}

Involvement of MAP kinases in apoptosis of different cell types has been identified ${ }^{[21-22]}$. However, it is still controversial ${ }^{[23-24]}$. MAPK pathway was evaluated in this study. Cell extracts were prepared from HT29 cells treated with C2-ceramide for different periods of time. As shown in Fig. 3A and Fig. 3B, p38 MAP kinase was activated in the relatively early stage (less than 12 $\mathrm{h}$ ), but was not so in the later stage (more than $12 \mathrm{~h}$ ). JNK was activated in the later stage, while ERK kept unchanged in the whole process, which was confirmed by the morphological change of HT29 cells pretreated with specific inhibitors, SB203580 and PD98059, respectively (Fig. 3C). Inhibition of p38, instead of ERK MAPK , could prevent the apoptosis induced by C2-ceramide treatment for $8 \mathrm{~h}$ (Fig. 3C). Nevertheless, in the relatively late stage $(>12 \mathrm{~h})$, inhibition of p38 MAPK by SB203580 was unable to inhibit the cell death induced by a long-term treatment with ceramide (24 h), which was also demonstrated by the DNA laddering data (Fig. 2D).

\section{NFкB Signaling in Ceramide-induced Apoptosis of HT29 Cells}

Nuclear factor kappa B $(\mathrm{NF} \kappa \mathrm{B})$ has been proposed as an anti-apoptotic factor, which plays a key role in cell survival and angiogenesis. However, there are also controversial reports. Therefore, we investigated the effect of ceramide on the activation of NFKB by Western blot assay and confocal microscopy, respectively. The results showed that p65 NFкB expression increased after the treatment with $\mathrm{C} 2$ and $\mathrm{C} 8$-ceramides for $24 \mathrm{~h}$ (Fig. 4A). The effect of $\mathrm{C} 2$-ceramide on the localization distribution of NFkB was studied using an indirect immunofluorescence assay and confocal microscopy. Control cells showed a resulting immunoreaction localized in cytoplasm of the cells. On the contrary, treatment with $30 \mu \mathrm{mol} / \mathrm{L} \mathrm{C} 2$-ceramide for $24 \mathrm{~h}$ led to pronounced nuclear translocation of $\mathrm{NF \kappa B}$. At the same time, nuclear structure was altered, accompanied 

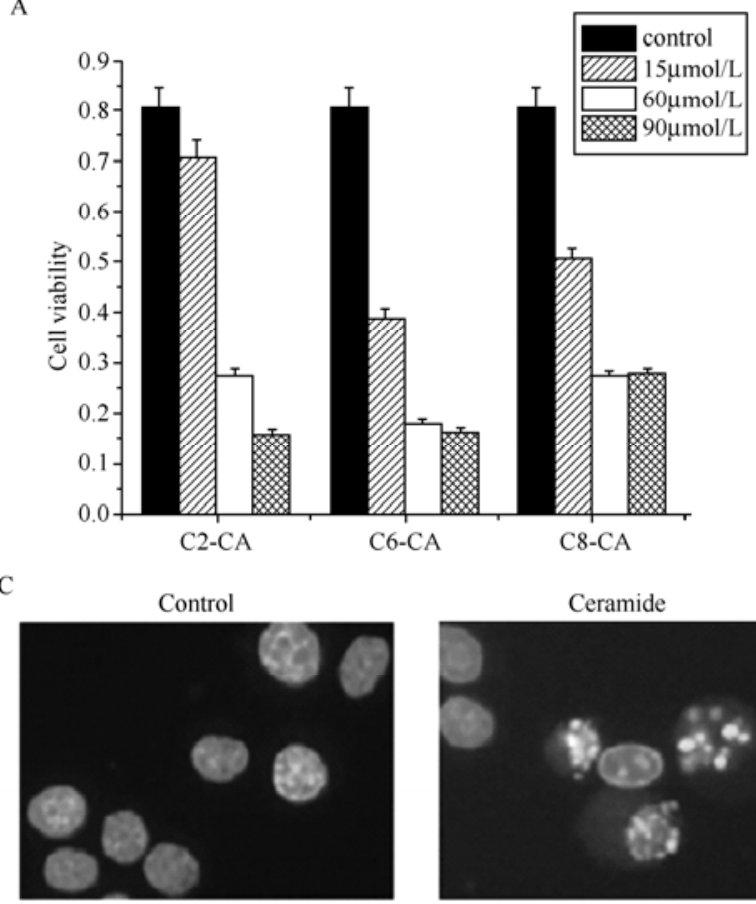

D

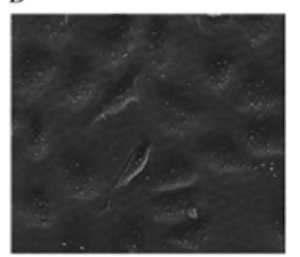

apoptolic body
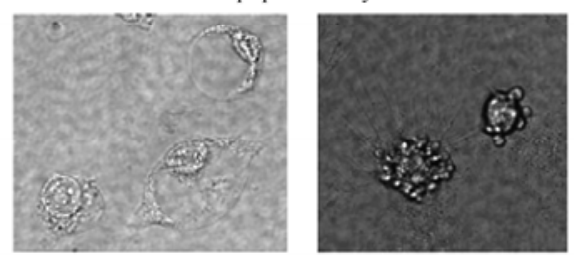

F

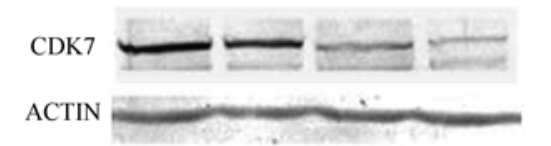

CT $\frac{5 \mu \mathrm{mol} / \mathrm{L} \quad 30 \mu \mathrm{mol} / \mathrm{L} 60 \mu \mathrm{mol} / \mathrm{L}}{\mathrm{C} 2-\mathrm{CA}}$

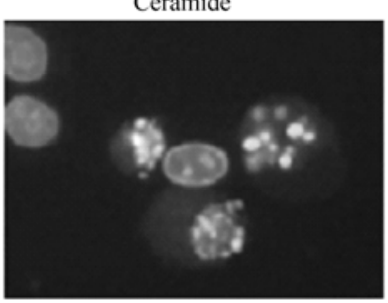

B

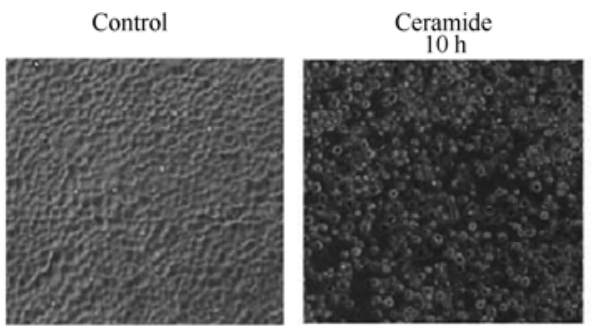

HT29 cells

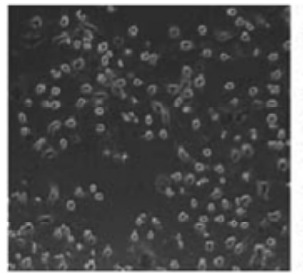

Ceramide

$18 \mathrm{~h}$

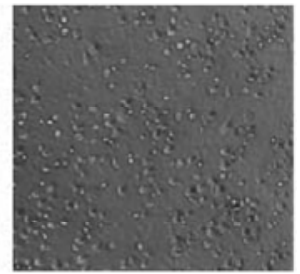

Ceramide

$24 \mathrm{~h}$

Control
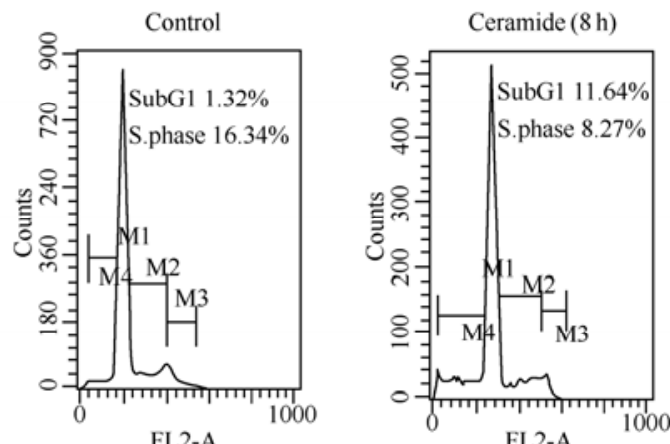

FL2-A
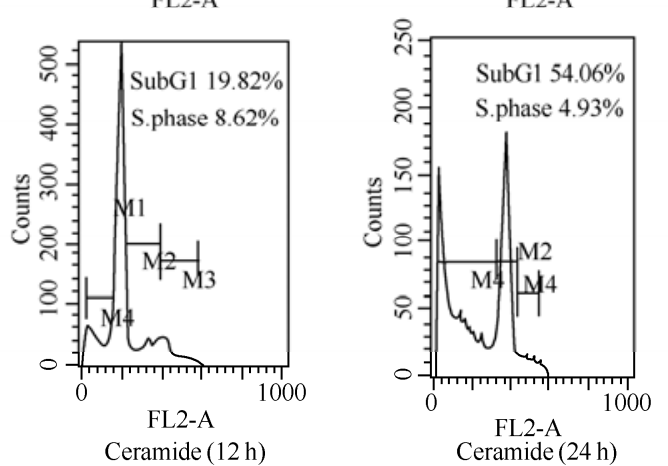

FIG. 1. Ceramide induces apoptosis in HT29 cells. A: Cells were cultured in a medium with different concentration of C2, C6, C8-ceramides for $24 \mathrm{~h}$. Cell viability was analyzed by MTT assay. B: Cells were cultured with $\mathrm{C} 2$-ceramide $(30 \mu \mathrm{mol} / \mathrm{L})$ for different periods of time. Proliferation inhibition was shown by microscopy $(\times 200)$. C and D: Cells were cultured with or without C2-ceramide $(30 \mu \mathrm{mol} / \mathrm{L})$. Apoptosis was demonstrated by HE staining method $(\times 400)(C)$. Apoptotic body was observed by microscopy $(\times 400)(D)$. E: Cells were cultured with $\mathrm{C} 2$-ceramide $(30 \mu \mathrm{mol} / \mathrm{L})$ for different periods of time. Apoptosis was detected by FACS assay with PI staining. F: Cells were cultured with different concentration of C2-ceramide for 24 h. CDK7 protein levels were measured by Western blot using anti-CDK7 antibody. The data were expressed as e $\bar{x} \pm s(n=3-4)$. 
A

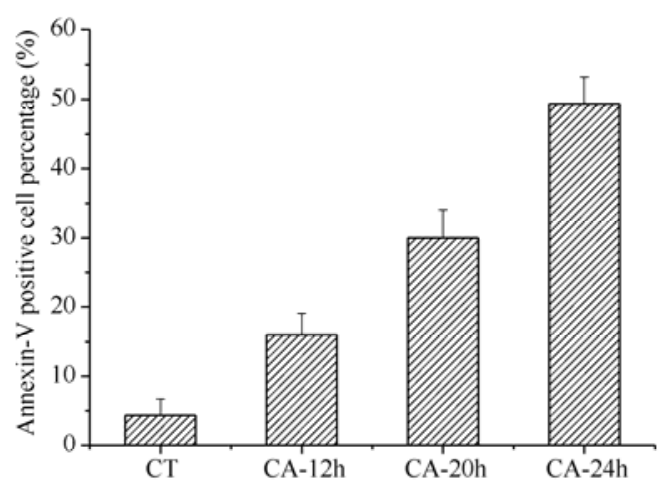

B

Cleaved-PARP

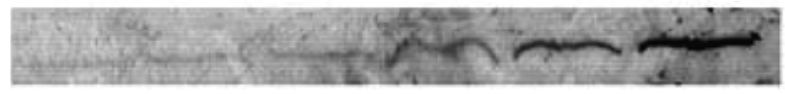

ACTIN

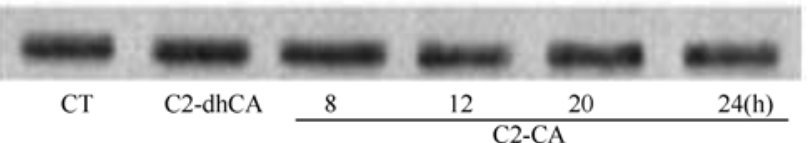

C

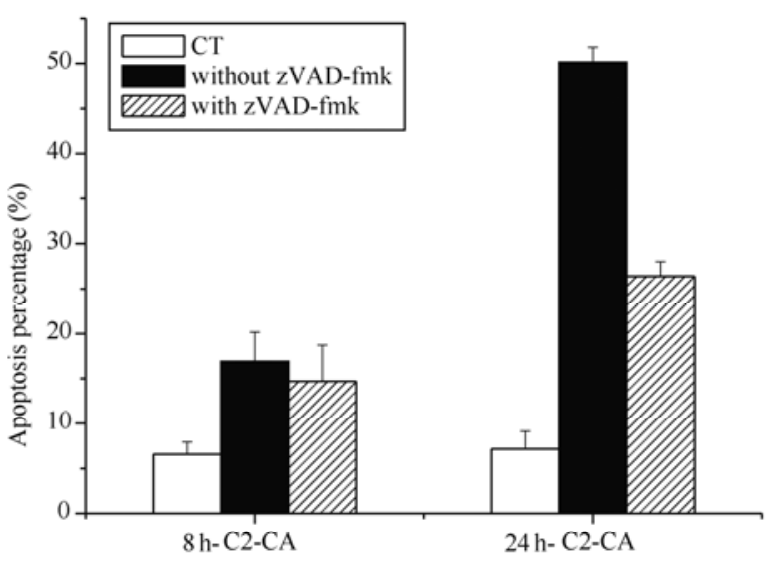

E
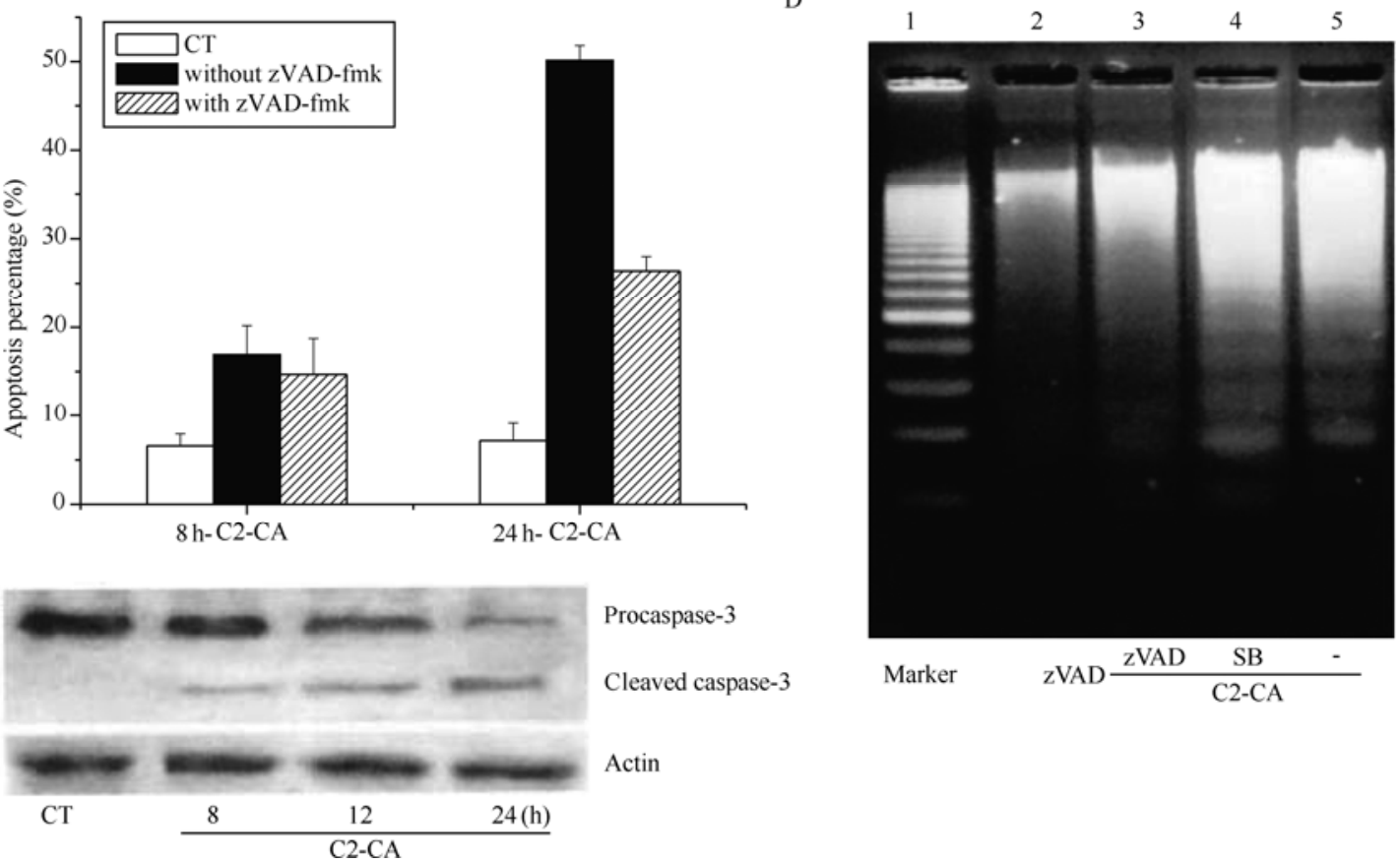

FIG. 2. Ceramide induces apoptosis via caspase-dependent and caspase-independent pathway. A: HT29 cells were cultured in a medium with $\mathrm{C} 2$-ceramide $(30 \mu \mathrm{mol} / \mathrm{L})$ for different periods of time as indicated. Apoptosis was detected by FACS assay with annexin V staining. The bar represents the relative number of apoptotic cells stained with annexin V. B: Cells were cultured in the medium with $\mathrm{C} 2$-ceramide $(30 \mu \mathrm{mol} / \mathrm{L})$ for different periods of time as indicated. Cleaved-PARP protein level was measured by Western blot using anti-cleaved-PARP antibody. C: Cells were cultured with or without $\mathrm{C} 2$-ceramide $(30 \mu \mathrm{mol} / \mathrm{L})$ in the presence or absence of zVAD-fmk for different periods of time as indicated. Apoptosis was detected by FACS assay with annexin V staining. The bar represents the relative number of apoptotic cells stained with annexin $\mathrm{V}$. The data were expressed as mean $\pm \mathrm{SE}$ $(n=3-4)$. D: Cells were cultured with or without C2-ceramide $(30 \mu \mathrm{mol} / \mathrm{L})$ in the presence or absence of zVAD-fmk and p38 MAPK inhibitor SB203580 for $24 \mathrm{~h}$. Genomic DNA was extracted and resolved on $1.5 \%$ agarose gel. E: Cells were cultured in amedium with $\mathrm{C} 2$-ceramide $(30 \mu \mathrm{mol} / \mathrm{L})$ for different periods of time as indicated. Procaspase- 3 and cleaved caspase- 3 levels were measured by Western blot using specific antibody. 
with condensed chromatin, a phenomena indicating apoptosis (Fig. 4B), which was confirmed by Western blot assay of different parts of cells treated with C2-ceramide for $24 \mathrm{~h}$ (Fig. 4B, bottom line). The results of the reported assay indicated that NFאB was activated when cells were treated with C2-ceramide, which was down-regulated when cells

A

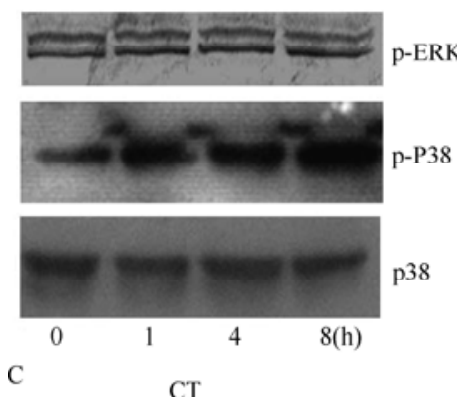

C
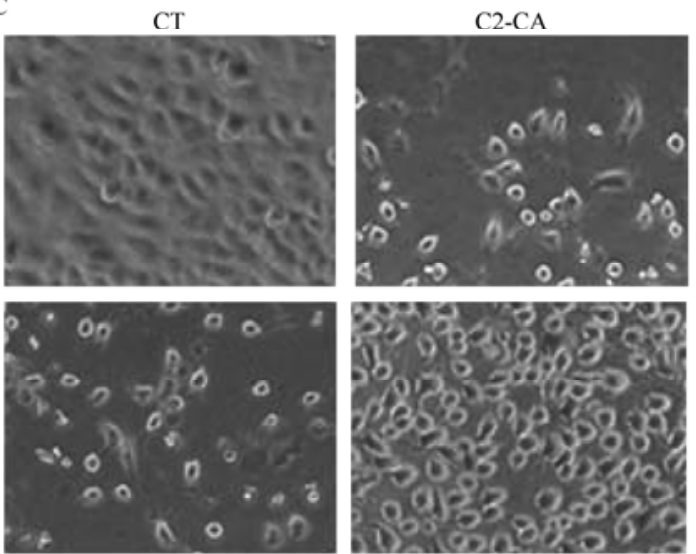

C2-CA+PD98059

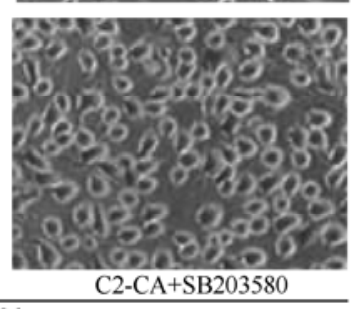

$8 \mathrm{~h}$ were pretreated with PDTC, an inhibitor of $\kappa \mathrm{B}$ from the cytoplasmic IкB-NFkB complex (Fig. 4C). As detected by MTT assay, the cytotoxicity of HT29 cells was enhanced when cells were pretreated with PDTC, followed by the treatment with $\mathrm{C} 2$-ceramide. The cytotoxicity in the relatively late stage was displayed in a dose- and time-dependent manner (Fig. 4D and Fig. 4E). B
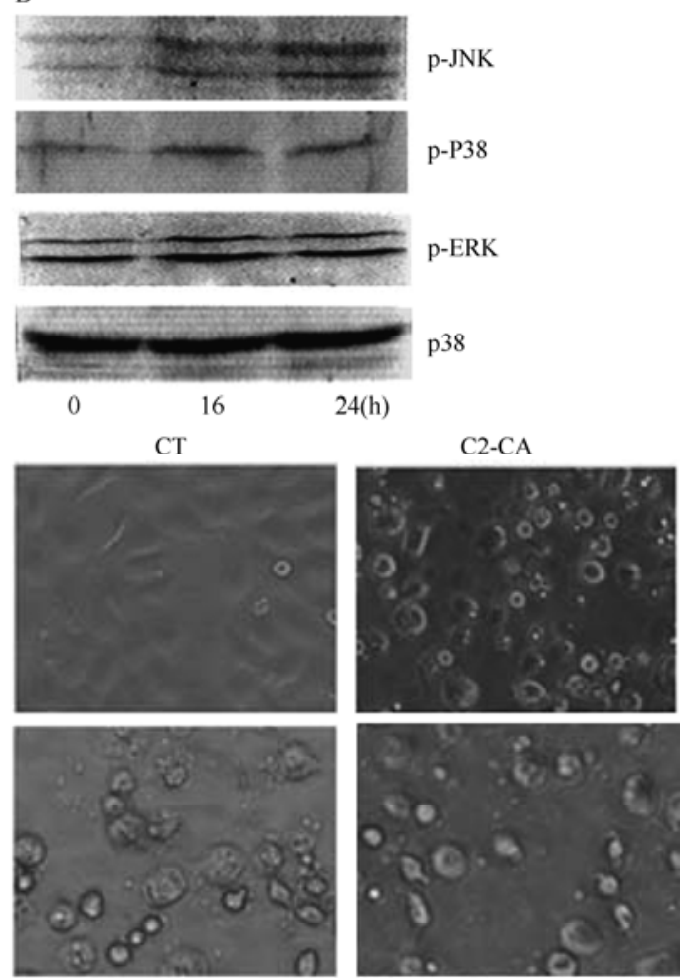

C2-CA+PD98059

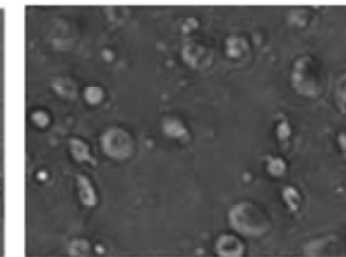

$\mathrm{C} 2-\mathrm{CA}+\mathrm{SB} 203580$

FIG. 3. MAPK signaling in ceramide-induce apoptosis of HT29 cells. A and B: Cells were cultured in the medium with $\mathrm{C} 2$-ceramide $(30 \mu \mathrm{mol} / \mathrm{L})$ for different periods of time as indicated. Total proteins were extracted and resolved on SDS-PAGE followed by Western blot assay using anti-phospho JNK, ERK and p38 antibodies. Data shown in Fig. 3A are in the relatively earlier stage $(0,1,4,8(\mathrm{~h}))$, data that the JNK was not activated were not shown, and data shown in Fig. 3B are in the late stage, which are more than $12 \mathrm{~h}(0,16,24(\mathrm{~h}))$. C: Cells were pretreated with PD98059 and SB203580 for $30 \mathrm{~min}$, respectively, and cultured in the medium with $30 \mu \mathrm{mol} / \mathrm{L}$ of $\mathrm{C} 2$-ceramide for 8 and $24 \mathrm{~h}$, respectively. Morphological changes of cells were then observed under microscope $(\times 400)$.

A
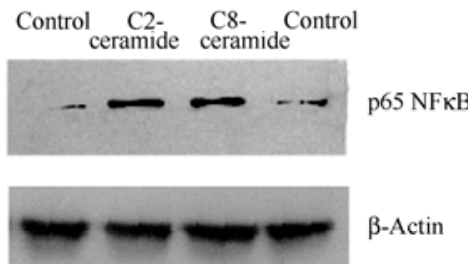

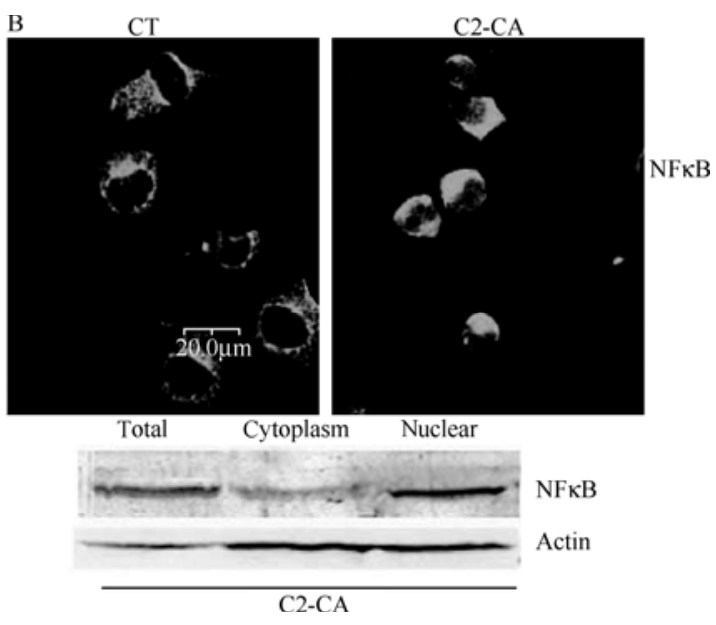


$\mathrm{C}$

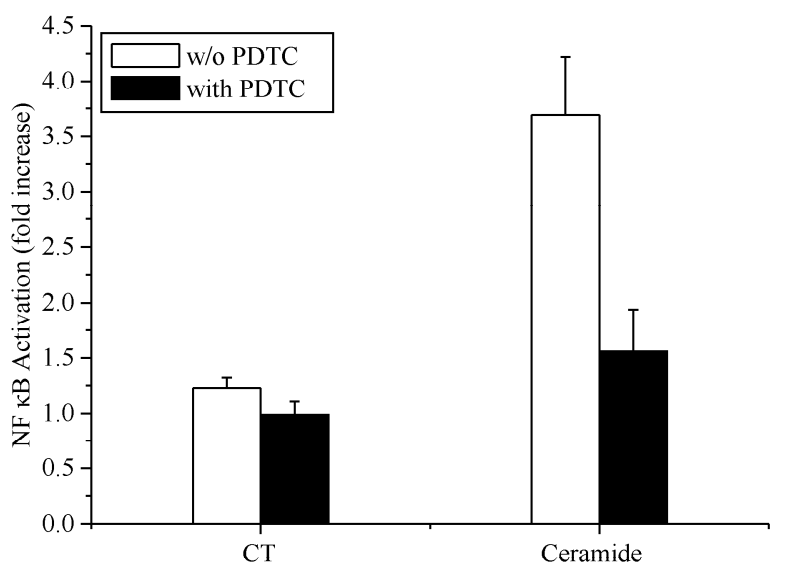

$\mathrm{E}$

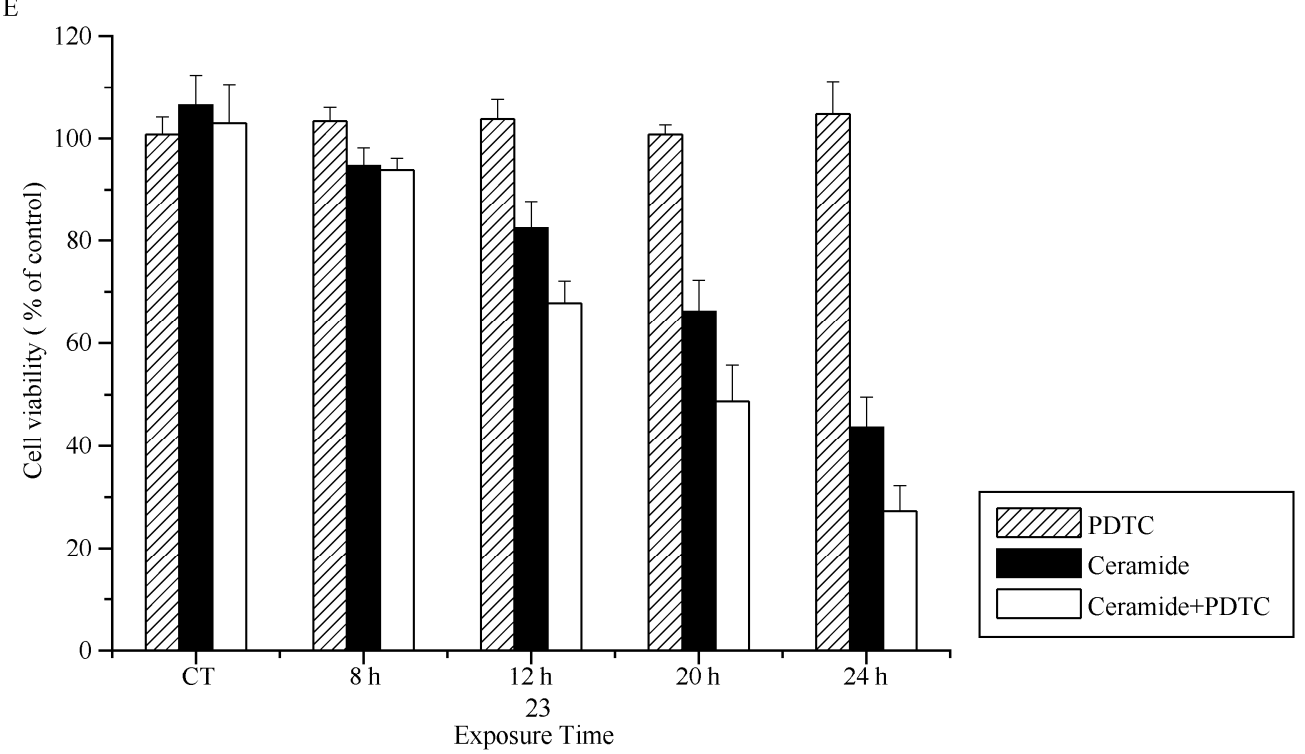

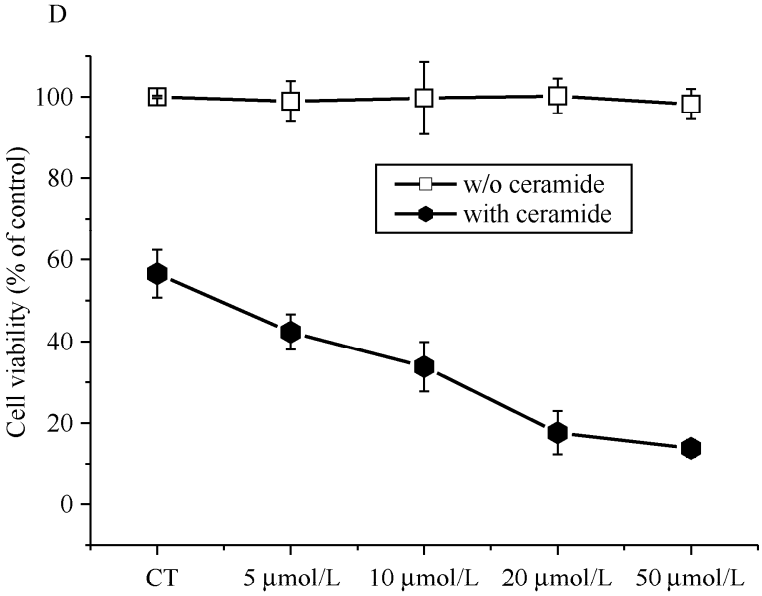

FIG. 4. NFkB involved in ceramide-induced apoptosis of HT29 cells. A: Cells were cultured with or without $30 \mu \mathrm{mol} / \mathrm{L}$ of $\mathrm{C} 2$, C8-ceramide for 24 h. p65 NFkB fragment protein level was measured by Western blot using anti- p65 NFkB and $\beta$-actin antibodies. B: Cells were cultured with or without $30 \mu \mathrm{mol} / \mathrm{L}$ of $\mathrm{C} 2$-ceramide for $24 \mathrm{~h}$. NFkB translocation from cytoplasm to nuclear was observed under confocal microscope after cells were fixed and used for immunohistochemistry assay. C: Cells were pretreated with PDTC, cultured with $30 \mu \mathrm{mol} / \mathrm{L}$ of C2-ceramide for $24 \mathrm{~h}$, transiently transfected with $\mathrm{NF} \kappa \mathrm{B}$ reporter or the control vector. NFאB transcriptional activity was measured as described. The bar represents the relative fold increase in luciferase activity. The data were expressed as $\bar{x} \pm s(n=3-4)$. D. Cells were cultured with 30 $\mu \mathrm{mol} / \mathrm{L}$ of C2-ceramide in the presence or absence of PDTC with different concentrations for $24 \mathrm{~h}$. Cell viability was determined by MTT assay. E: Cells were cultured with C2-ceramide in the presence or absence of PDTC (20 $\mu$ mol/L) for different periods of time. Cell viability was determined by MTT assay. The data were expressed as $\bar{x} \pm s(n=3-4)$.

\section{DISCUSSION}

Apoptosis is mediated by various cellular events including protein synthesis and degradation, alteration in protein phosphorylation status, activation of lipid second messenger systems and disruption of mitochondria function. Recently, ceramide has shown its inhibitory effect on cell growth via apoptosis in a variety of cancers, since it was confirmed as an important lipid second messenger in 1994. However, its mechanism is not yet clearly understood. In this study, ceramide could induce caspase-dependent and -independent apoptosis involved in activation of p38 MAP kinase or NFkB, which was modulated by different mechanisms in different periods of treatment.

It has been shown that ceramide is able to activate a genetically regulated suicide program. Ceramide-induced cell death varies with cell types and cellular environment, demonstrating that cellular 
context and environment may contribute to the types of cell death induced by ceramide. In our study, ceramide could induce apoptosis of HT29 cells, which was demonstrated by HE staining, formation of apoptotic bodies and accumulation of percentage of SubG1 phase, respectively. It has been reported that ceramide acts as a cell cycle suppressor that can lead to $\mathrm{G} 1 / \mathrm{G} 0$ arrest $^{[25-27]}$. In this study, S phase cells were decreased after the treatment with ceramide. Moreover, decrease in S phase cells is associated with an increase in sub-G1 DNA contents, indicating that DNA cleavage and caspase-dependent apoptosis are induced. It is reported that $\mathrm{CDK} 7$ in nuclei and cytoplasm is attached to DNA template with other TFH subunits initiating gene transcription ${ }^{[28]}$, which is pivotal to modulate cell proliferation. In our study, C2-ceramide treatment obviously inhibits CDK7 expression, indicating that $\mathrm{CDK} 7$ alteration may contribute to the effect of C2-ceramide on cell cycle distribution alteration.

In the present study, caspase-independent apoptosis is induced by a short-time treatment with ceramide, followed by caspase-dependent and -independent apoptosis. The caspase-independent apoptosis occurring in the early stage could not be determined by classic phenotypes of apoptosis. However, in the relatively late stage (more than $12 \mathrm{~h}$ ), C2-ceramide enhanced PARP cleavage and cleaved caspase-3, are presumably attributed to enhanced caspase activity, suggesting that caspase-dependent and -independent apoptosis occurs in the late stage.

Involvement of cell signaling is further investigated. Activation of MAP kinase pathway is involved in apoptosis of different cells, such as PC12 death induced by NGF withdrawal ${ }^{[21]}$ and $\mathrm{H}_{2} \mathrm{O}_{2}$ stress $^{[22]}$ and $\mathrm{T}$ cell apoptosis induced by glucocorticoid $^{[29]}$. In our experimental model, the activation of p38 and JNK is observed in HT29 cells treated with $\mathrm{C} 2$-ceramide $(30 \mu \mathrm{mol} / \mathrm{L})$ for different periods of time. Although ERK MAP kinase can be down-regulated by ceramide in some cell lines, our data have demonstrated that $\mathrm{C} 2$-ceramide fails to affect phosphoration of ERK and total ERK proteins (Fig. 3A and 3B). A number of studies have reported that p38 MAPK is involved in the mediation of ceramide-induced cell death ${ }^{[8-9,30-31]}$. Nevertheless, no report supports the role of p38 MAPK in the mediation of ceramide-induced apoptosis ${ }^{[11-12]}$. Our data show that C2-ceramide could activate p38 MAPK phosphoration, which is consistent with the reports that sphingomyelinase and ceramide activate p38 in $184 \mathrm{~B} 5 /$ HER cells ${ }^{[32]}$ and NCI-H292 cells ${ }^{[6]}$. In our study, inhibition of ERK activation by MEK inhibitor PD98059 has no effect on ceramide-induced cell death, whereas inhibition of p38 MAP kinase by specific inhibitor SB203580 may suppress ceramide-induced death, indicating that p38 activation plays an important role in the capase-independent cell death induced by a short time treatment with ceramide. However, neither PD98059 nor SB203580 could affect the cell death induced by a long-term treatment with ceramide. On the contrary, capase inhibitor effectively, though not entirely, inhibites the DNA fragmentation induced by a long-term treatment with ceramide and partially inhibites PARP degradation. These results demonstrate that ceramide may have two different potential mechanisms underlying the apoptosis of HT29 cells. Although the mechanism remains to be further studied, differential signaling pathways might be involved in the regulation of ceramide-induced apoptosis. Apoptosis induced by long-term ceramide treatment involves caspase-dependent and -independent events and is associated with cell cycle-related signaling events, whereas caspase -independent apotosis induced by short-term ceramide treatment is mediated via the mechanism by which p38 MAPK plays an important role.

On the other hand, nuclear factor kappa B has been proposed as an anti-apoptotic factor, which plays a key role in cell survival and angiogenesis. $\mathrm{NF} \kappa \mathrm{B}$ is a protein factor which can specifically bind to the enhancer $\kappa \mathrm{B}$, and the latter is activated following transcriptional activation of specific genes when cells are exposed to various stresses, such as inflammatory media, virus infection and oxygen stresses. Previous studies have shown that there are three major mechanisms involved in apoptosis inhibition induced by the activation of NFKB which can induce the expression of TRAF1/2 (tumor necrotic factor receptor associated factors 1 and 2) and cellular endogenous anti-apoptotic proteins cIAP1/cIAP2: TNF receptor signaling pathway, induced-expression of anti-apoptotic genes (Bcl-2 and $\mathrm{Bcl}-\mathrm{xL}$ ), and accumulation of the expression of MnSOD.

This study has demonstrated that ceramide could activate the expression and activity of $\mathrm{NF \kappa B}$. It has been reported that use of acid- and neutralized-sphingomyelinase could lead to significant activation of $\mathrm{NF \kappa B}^{[33-34]}$, which is consistent with our findings. Many specific inhibitors of the NFאB signaling pathway have been used, such as Bay11-7085, SCH66336, PDTC, and lactacystin in the treatment of cancer patients with apoptosis ${ }^{[35-38]}$.

To gain more insights into the possible combined therapy correlated with inhibition of NFkB activation and cell death induction, experiments have been performed with PDTC, a compound that stimulates the cytotoxic impact of TNF-a on human Jurkat T-cells by suppressing the release of I $\mathrm{B}$ from latent $\mathrm{NF} \kappa \mathrm{B}$, due to a combination of antioxidant and heavy 
metal chelating properties ${ }^{[39]}$. Our data show that PDTC has increased the cytotoxicity of C2-ceramdie on HT29 cells, which supports the hypothesis that the intracellular signaling pathway triggered by C2-ceramide is NFKB-dependent and prevents cell death. It has been demonstrated that NF- $\kappa \mathrm{B}$ activation can inhibit caspase activity through the transcription of the c-iap gene ${ }^{[40]}$. Activation of NFKB by ceramide could explain why caspase activation is limited during ceramide-induced apoptosis.

However, some scientists hold that certain neuron cells result in apoptosis because of the expression of pre-apoptotic genes induced by activation of NFKB. Clemens et al. ${ }^{[41]}$ have demonstrated that sustained activation of NFאB leads to accumulation of apoptosis in hippocampus nerve cells after $7 \mathrm{~h}$ of mouse transient cerebral ischemia. Shou et $a l^{[42]}$ have also reported that activation of $\mathrm{NF} \kappa \mathrm{B}$ could induce expression of pre-apoptotic proteins, Bcl-Xs and Bax, but has no effect on anti-apoptotic proteins, Bcl-2 or Bcl-xL, resulting in apoptosis. The modulation of activation of $\mathrm{NF} \kappa \mathrm{B}$ is complex. Further study is needed.

In summary, ceramide-induced apoptotic cell death involves caspase-dependent and -independent signaling pathway. Caspase-independent cell death occurring in the relatively early stage, which is mediated by $\mathrm{p} 38$ MAP kinase, can progress into a stage involving caspase-dependent and -independent mechanisms, as well as cell signaling of MAPKs and NFkB.

\section{REFERENCES}

1. Kolesnick R N, Kronke M (1998). Regulation of ceramide production and apoptosis. Annu Rev Physiol 60, 643-665.

2. Bose R, Verheij M, Haimovitz-Friedman A, et al. (1995). Ceramide synthase mediates daunorubicin-induced apoptosis: an alternative mechanism for generating death signals. Cell 82, 405-414.

3. Noda S, Yoshimura S, Sawada M, et al. (2001). Role of ceramide during cisplatin-induced apoptosis in C6 glioma cells. $J$ Neurooncol 52, 11-21.

4. Selzner M, Bielawska A, Morse M A, et al. Clavien P A (2001). Induction of apoptotic cell death and prevention of tumor growth by ceramide analogues in metastatic human colon cancer. Cancer Res 61, 1233-1240.

5. Verheij M, Bose R, Lin X H, et al. (1996). Requirement for ceramide-initiated SAPK/JNK signalling in stress-induced apoptosis. Nature 380, 75-79.

6. Chen C C, Sun Y T, Chen J J, et al. (2001). Tumor necrosis factor-alpha-induced cyclooxygenase-2 expression via sequential activation of ceramide-dependent mitogen-activated protein kinases, and IkappaB kinase $1 / 2$ in human alveolar epithelial cells. Mol Pharmacol 59, 493-500.

7. Gouaze V, Mirault M E, Carpentier S, et al. (2001). Glutathione peroxidase-1 overexpression prevents ceramide production and partially inhibits apoptosis in doxorubicin-treated human breast carcinoma cells. Mol Pharmacol 60, 488-496.

8. Brenner B, Koppenhoefer U, Weinstock C, et al. (1997). Fas- or ceramide-induced apoptosis is mediated by a Rac1-regulated activation of Jun N-terminal kinase/p38 kinases and GADD153. $J$ Biol Chem 272, 22173-22181.

9. Hida H, Nagano S, Takeda M, et al. (1999). Regulation of mitogen-activated protein kinases by sphingolipid products in oligodendrocytes. J Neurosci 19, 7458-7467.

10. Caricchio R, D'Adamio L, Cohen P L (2002). Fas, ceramide and serum withdrawal induce apoptosis via a common pathway in a type II Jurkat cell line. Cell Death Differ 9, 574-580.

11. Scheid M P, Foltz I N, Young P R, et al. (1999). Ceramide and cyclic adenosine monophosphate (cAMP) induce cAMP response element binding protein phosphorylation via distinct signaling pathways while having opposite effects on myeloid cell survival. Blood 93, 217-225.

12.Jarvis W D, Fornari F A Jr, Auer K L, et al. (1997). Coordinate regulation of stress- and mitogen-activated protein kinases in the apoptotic actions of ceramide and sphingosine. Mol Pharmacol 52, 935-947.

13. Demarchi F, Bertoli C, Greer P A, et al. (2005). Ceramide triggers an NF-kappaB-dependent survival pathway through calpain. Cell Death Differ 12, 512-522.

14. Wang C Y, Mayo M W, Baldwin A S Jr (1996). TNF- and cancer therapy-induced apoptosis: potentiation by inhibition of NF-kappaB. Science 274, 784-787.

15. France-Lanord V, Brugg B, Michel P P, et al. (1997). Mitochondrial free radical signal in ceramide-dependent apoptosis: a putative mechanism for neuronal death in Parkinson's disease. J Neurochem 69, 1612-1621.

16. Wang Y, Qin Z H, Nakai M, et al. (1999). Co-stimulation of cyclic-AMP-linked metabotropic glutamate receptors in rat striatum attenuates excitotoxin-induced nuclear factor-kappaB activation and apoptosis. Neuroscience 94, 1153-1162.

17. Siskind L J (2005). Mitochondrial ceramide and the induction of apoptosis. J Bioenerg Biomembr 37, 143-153.

18.Gulbins E (2003). Regulation of death receptor signaling and apoptosis by ceramide. Pharmacol Res 47, 393-399.

19. Matsunaga T, Kotamraju S, Kalivendi S V, et al. (2004). Ceramide-induced intracellular oxidant formation, iron signaling, and apoptosis in endothelial cells: protective role of endogenous nitric oxide. $J$ Biol Chem 279, 28614-28624.

20. Wang J, Lv X, Shi J, et al. (2006). Ceramide induces apoptosis via a peroxisome proliferator-activated receptor gamma-dependent pathway. Apoptosis 11, 2043-2052.

21.Derijard B, Hibi M, Wu I H, et al. (1994). JNK1: a protein kinase stimulated by UV light and Ha-Ras that binds and phosphorylates the c-Jun activation domain. Cell 76, 1025-1037.

22.Han J, Lee J D, Bibbs L, et al. (1994). A MAP kinase targeted by endotoxin and hyperosmolarity in mammalian cells. Science 265, 808-811.

23. Hu E, Kim J B, Sarraf P, et al. (1996). Inhibition of adipogenesis through MAP kinase-mediated phosphorylation of PPARgamma. Science 274, 2100-2103.

24. Rosen E D, Walkey C J, Puigserver P, et al. (2000). Transcriptional regulation of adipogenesis. Genes Dev 14, 1293-1307.

25.Dbaibo G S, Pushkareva M Y, Jayadev S, et al. (1995). Retinoblastoma gene product as a downstream target for a ceramide-dependent pathway of growth arrest. Proc Natl Acad Sci U S A 92, 1347-1351.

26. Hannun Y A (1996). Functions of ceramide in coordinating cellular responses to stress. Science 274, 1855-1859.

27.Lee J Y, Leonhardt L G, Obeid L M (1998). Cell-cycledependent changes in ceramide levels preceding retinoblastoma protein dephosphorylation in G2/M. Biochem $J 334$ ( $\mathrm{Pt} 2$ ), 457-461.

28.Chen J, Larochelle S, Li X, et al. (2003). Xpd/Ercc2 regulates CAK activity and mitotic progression. Nature 424, 228-232.

29. Han J, Lee J D, Tobias P S, et al. (1993). Endotoxin induces rapid protein tyrosine phosphorylation in $70 \mathrm{Z} / 3$ cells expressing CD14. J Biol Chem 268, 25009-25014. 
30. Shimizu H, Banno Y, Sumi N, et al. (1999). Activation of p38 mitogen-activated protein kinase and caspases in UVB-induced apoptosis of human keratinocyte $\mathrm{HaCaT}$ cells. $J$ Invest Dermatol 112, 769-774.

31. Willaime S, Vanhoutte $\mathrm{P}$, Caboche $\mathrm{J}$, et al. (2001). Ceramide-induced apoptosis in cortical neurons is mediated by an increase in p38 phosphorylation and not by the decrease in ERK phosphorylation. Eur J Neurosci 13(11), 2037-2046.

32. Subbaramaiah K, Chung W J, Dannenberg A J (1998). Ceramide regulates the transcription of cyclooxygenase- 2 . Evidence for involvement of extracellular signal-regulated kinase/c-Jun N-terminal kinase and p38 mitogen-activated protein kinase pathways. J Biol Chem 273, 32943-32949.

33. Colell A, Coll O, Mari M, et al. (2002). Divergent role of ceramide generated by exogenous sphingomyelinases on NF-kappa B activation and apoptosis in human colon HT-29 cells. FEBS Lett 526, 15-20.

34. Lee C W, Lin C C, Lin W N, et al. (2007). TNF-alpha induces MMP-9 expression via activation of Src/EGFR, PDGFR/PI3K/Akt cascade and promotion of NF-kappaB/p300 binding in human tracheal smooth muscle cells. Am J Physiol Lung Cell Mol Physiol 292, L799-812.

35.Relic B, Benoit V, Franchimont N, et al. (2004). 15-deoxy-delta12,14-prostaglandin J2 inhibits Bay 11-7085-induced sustained extracellular signal-regulated kinase phosphorylation and apoptosis in human articular chondrocytes and synovial fibroblasts. J Biol Chem 279, 22399-22403.

36. Han J Y, Oh S H, Morgillo F, et al. (2005). Hypoxia-inducible factor 1alpha and antiangiogenic activity of farnesyltransferase inhibitor SCH66336 in human aerodigestive tract cancer. $J$ Natl Cancer Inst 97, 1272-1286.

37.Ziegler-Heitbrock H W, Sternsdorf T, Liese J, et al. (1993). Pyrrolidine dithiocarbamate inhibits NF-kappa B mobilization and TNF production in human monocytes. J Immunol 151, 6986-6993.

38. Cory A H, Cory J G (2002). Lactacystin, a proteasome inhibitor, potentiates the apoptotic effect of parthenolide, an inhibitor of NFkappaB activation, on drug-resistant mouse leukemia L1210 cells. Anticancer Res 22, 3805-3809.

39. Schreck R, Meier B, Mannel D N, et al. (1992). Dithiocarbamates as potent inhibitors of nuclear factor kappa B activation in intact cells. $J$ Exp Med 175, 1181-1194.

40.Wang C Y, Mayo M W, Korneluk R G, et al. (1998). NF-kappaB antiapoptosis: induction of TRAF1 and TRAF2 and c-IAP1 and c-IAP2 to suppress caspase- 8 activation. Science 281, 1680-1683.

41.Clemens J A, Stephenson D T, Yin T, et al. (1998). Drug-induced neuroprotection from global ischemia is associated with prevention of persistent but not transient activation of nuclear factor-kappaB in rats. Stroke 29, 677-682.

42. Shou Y, Li N, Li L, et al. (2002). NF-kappaB-mediated up-regulation of $\mathrm{Bcl}-\mathrm{X}(\mathrm{S})$ and $\mathrm{Bax}$ contributes to cytochrome $\mathrm{c}$ release in cyanide-induced apoptosis. J Neurochem $\mathbf{8 1}, 842-852$.

(Received June 28, 2008 Accepted November 21, 2008) 